\title{
ATRIBUTOS FÍSICOS E CARBONO ORGÂNICO DE UM ARGISSOLO VERMELHO SOB SISTEMAS DE MANEJ $\mathbf{O}^{(\mathbf{1})}$
}

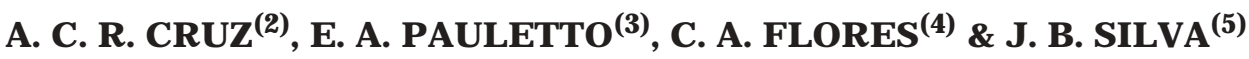

\begin{abstract}
RESUMO
O objetivo deste trabalho foi avaliar as propriedades físicas e carbono orgânico de um Argissolo Vermelho, em Pelotas (RS), submetido a sistemas de manejo numa propriedade agrícola. Avaliaram-se densidade do solo, porosidade total, macro e microporosidade, granulometria, argi la dispersa em água, diâmetro médio ponderado de agregados e infiltração de água, bem como carbono orgânico. Foram estudados os sistemas: plantio direto com três anos de condução, com aveia +ervilhaca no inverno e mi lho no verão; si stema convencional (uma aração e uma gradagem) com aveia como cobertura de inverno e mil ho no verão; sistema convencional, com ervil haca +aveia no inverno e mil ho no verão, e campo nativo. Observou-se que o solo sob os sistemas convencionais apresentou maior porosidade total e macroporosidade na profundidade de $0,0-0,10 \mathrm{~m}$ e maior microporosidade na profundidade de $0,10-0,20 \mathrm{~m}$. Os maiores valores de densidade do solo na profundidade de $0,0-0,10 \mathrm{~m}$ foi no solo sob plantio direto. Houve aumento do teor de carbono orgânico do solo no sistema plantio direto na camada de 0,0-0,10 m em relação aos outros sistemas avaliados, não resultando em aumento no diâmetro médio ponderado dos agregados.
\end{abstract}

Termo de indexação: plantio direto, estrutura do solo, agregação do solo, densidade do solo.

(1) Parte da Tese de Mestrado do primeiro autor, apresentada à FAEM, Universidade Federal de Pelotas - UFPel. Recebido para publicação em abril de 2002 e aprovado em setembro de 2003.

(2) Engenheiro-Agronômo, Dr. em Solos e Nutrição de Plantas. Rua XV de novembro 302/503, CEP 96015-000 . Pelotas (RS). E-mail: toncruz11@ig.com.br

(3) Professor Adjunto do Departamento de Solos, Universidade Federal de Pelotas - UFPel. Campus Universitário, Caixa Postal 354, CEP 96010-970 Pelotas (RS). E-mail: pauletto@ufpel.tche.br

(4) Pesquisador II da Emprapa/Clima Temperado. BR 392, Km 78, Caixa Postal 403, CEP 96001-970 Pelotas (RS). E-mail: cflores@terra.com.br

(5) Professor Titular do Departamento de Matemática e Estatística, UFPel. E-mail: jbsilva@ufpel.tche.br 


\title{
SUMMARY: PHYSICAL ATTRIBUTES AND ORGANIC CARBON OF A TYPIC HAPLUDALF UNDER SOIL MANAGEMENT SYSTEMS
}

\begin{abstract}
Theobjectiveof this research was to evaluatethephysi cal properties and organic carbon of a Typic Hapludalf in Pelotas, State of Rio Grande do Sul, Brazil, under different soil management systems on a farm. The assessed physical attributes were: soil bulk density, total porosity, macro and microporosity, particle size distribution, water dispersed clay, mean weight diameter of water-stable aggregates, and soil water infiltration, as well as organic carbon, in a factorial schemein a completely randomized design with six replications. Themanagement systems werestudi ed for threeyears: no-tillagesystem with oats + vetch in winter and corn in summer; conventional tillage system with oat winter covering and corn in summer; conventi onal tillage (once plowing and oncedisking) with oats + vetch in winter and corn in summer; and native grassland. It was observed that soil under conventional tillage systems presented a higher total porosity and macroporosity in the $0.0-0.10 \mathrm{~m}$, but higher mi croporosity in the $0.10-0.20 \mathrm{~m}$ layer; the no-tillage system presented the greatest values of soil bulk density in the 0.0-0.10 mlayer. Therewas an increasein thesoil organic carbon content for the no-till agesystem, which was not reflected in an increasein themean weight diameter of the water-stableaggregates.
\end{abstract}

Index terms: no-tillage, soil structure, soil aggregation, bulk density.

\section{NTRODUÇÃO}

A estrutura do solo é o alvo do manejo físico do solo. Embora não seja considerada em si um fator de crescimento para as plantas, exerce influência na disponibilidadedeágua ear às raízes das plantas, no suprimento e no desenvolvimento do sistema radicular (Palmeira et al., 1999).

A perda de condições desejáveis do solo, relacionadas com o crescimento de plantas e ambiente, tem sido considerada como degradação do solo (Reinert, 1997). Esta definiç̧ão refere-se à perda de produtividade dos solos decorrentes da diminuição de quantidades de nutrientes, matéria orgânica, mudanças em atributos físicos e outras conseqüências adversas. Esta degradação da estrutura do sol o causa perda de condi ções favoráveis ao desenvolvimento vegetal e predispõe o solo à erosão hídrica acelerada (Albuquerque et al., 1995).

Segundo Denardin \& Kochhann (1997), as mobilizações intensivas do solo, no sistema convencional, sob condições inadequadas de umi dade e de cobertura vegetal, modificam adversamente a estrutura do solo, afetando basicamente as rel ações entre as fases: sólida, líquida egasosa. Desta forma, transformam a camada arável em: a superficial pulverizada e a subsuperficial compactada. Entretanto, o sistema plantio direto é um sistema de produção agrícola em que a semeadura das culturas é feita sem preparo do solo, mantendo os restos culturais dos cultivos anteriores na superfície. Esse sistema de manejo é eficaz na proteção da superfície do solo contra agentes erosivos, mas como não há revolvimento do solo, pode ocorrer a formação de camadas compactadas na distribuição das pressões exercidas na superfície do solo pelas máquinas/ implementos ou casco de animais, em áreas de integração lavoura-pecuária. O aumento da densidade do solo em lavouras sob este sistema foi verificado por vários autores podendo ser consi derado como uma conseqüência natural do sistema plantio direto (Reinert, 1990; Silva \& Mielniczuk, 1997).

Outro parâmetro importante na avaliação da qualidade estrutural de um solo é a infiltração de água. Barcel os et al. (1999) relataram que os preparos conservacionistas de solo (sistema plantio direto e cultivo mínimo) resultaram em capacidades de infiltração de água no solo, avaliadas pelo método da chuva simulada, superiores às do preparo convencional, exceto no período imediatamente após o preparo de solo e, ou, semeadura da aveia em sucessão ao milho.

Abrão et al. (1979), por outro lado, utilizando o método dos cilindros concêntricos, encontraram taxas iniciais de infiltração maiores nos sistemas convencionais de manejo em relação aos sistemas com menor mobilização do solo, estudando efeitos desistemas de preparo do sol o sobreas características físicas de um Latossol o Roxo Distrófico, em l juí (RS).

O objetivo do presente trabal ho foi avaliar as propriedades físicas e carbono orgânico de um Argissolo Vermel ho sob os sistemas de manejo convencional, plantio direto e campo nativo, numa propriedade agrícola.

\section{MATERIAL E MÉTODOS}

Realizou-seo presentetrabal ho numa propriedade agrícola local izada na microbacia do Passo do Pilão, cerca de $20 \mathrm{~km}$ noroeste da sede do município de 
Pelotas (RS). Esta área encontra-se na região fisiográfica da Encosta do Sudeste do Rio Grande do Sul e o clima da região, de acordo com a classificação climática de Köppen, é do tipo Cfa2, ou seja, subtropical úmido sem estiagens. A precipitação média anual varia de 1.185 a $1.364 \mathrm{~mm}$ e a temperatura do mês mais quente é superior a $22^{\circ} \mathrm{C}$ e do mês mais frio varia de 3 a $18^{\circ} \mathrm{C}$ (Mota et al. 1986). A área escol hida abrange 21,0 ha, sendo 10,0 ha de lavouras, 8,0 ha de pastagens, 2,0 ha de mata nativa e 1,0 ha correspondendo à área da sede e instalações rurais. A área faz parte do monitoramento do sistema plantio direto da E mbrapa/Centro de Pesquisa Agropecuária deClima Temperado desde 1995 e começou com a instalação das culturas de aveia preta e ervilhaca peluda no inverno. Esse solo foi anteriormente escarificado para quebrar possível camada compactada formada por vários anos desistema convencional, comotambém foi corrigido o pH (3,6 t ha-1 de calcário), fósforo (125 kg ha-1 de $\mathrm{P}_{2} \mathrm{O}_{5}$ ) e potássio ( $25 \mathrm{~kg} \mathrm{ha}^{-1}$ de $_{2} \mathrm{O}$ ).

Como objeto de estudo, foram escol hidas duas parcelas cultivadas sob o sistema convencional com diferenças nas coberturas de inverno empregadas: uma parcela de 0,2 ha com seqüência no inverno de aveia preta (sistema convencional 1-SC1), e outra parcela com cultivo de aveia preta consorciada com ervilhaca (sistema convencional 2-SC2) e uma parcela sob sistema de plantio direto de 0,2 ha, com cultivo de milho no verão e ervil haca peluda e aveia preta no inverno. No inverno, foram efetuadas coberturas de aveia e aveia mais ervilhaca, cujo manejo nas áreas convencionais constituiu-se de incorporação da cobertura, antes do plantio de verão, e na área sob sistema plantio direto, constituiu-se de dessecação com glifosato. Como referência, foi escol hida uma área de campo nativo, utilizada como potreiro (lotação de 1 U A ha-1) deaproximadamente 0,3 ha, formado principal mente por grama forquilha (Paspalum notatum) e desmódio (Desmodium adscendens). O solo da referida área foi classificado como Argissolo Vermel ho (EMBRAPA, 1999). No quadro 1, são apresentados os resultados deanál ises químicas realizadas em amostras col etadas na área.

Em outubro de 1998, foram efetuadas as coletas de amostra deformadas e indeformadas em triplicata, em seis locais distintos e distanciados de 15 m entre si para cada sistema demanejo. As amostras indeformadas foram coletadas com anéis de volume de aproximadamente $100 \mathrm{~cm}^{3}$, em duas profundidades: $(0,0-0,10$ e 0,10-0,20 m). Estes anéis foram utilizados nas determinações de densidade do sol o pel o método do anel volumétrico (Blake \& Hartge, 1986), macroporosidade, microporosidade e porosidade total pelo método da mesa de tensão (EMBRAPA, 1997). Amostras deformadas, col etadas nos mesmos locais anteriormente citados, foram acondicionadas em sacos plásticos elevadas ao Laboratório de Física do solo da Embrapa/CPACT, passadas em peneira de 2 e 9,52 mm e secas ao ar e serviram para as determinações de granulometria pelo método da pipeta (Gee \& Bauder, 1986), diâmetro médio ponderado de agregados pelo método de Kemper \& Chepil, 1986, modificado por Palmeira et al., 1999. Nesta última avaliação, as peneiras utilizadas constituíam-se de 4,76, 2,00, 1,00, 0,50 e 0,25 mm de abertura de malha, sendo o umedecimento realizado por capilaridade e o tempo de peneiramento de 10 min (30 oscilações por minuto).

Para as análises do conteúdo de carbono orgânico (método Walkley-Black, descrito por Allison, 1965, citado por Tedesco et al., 1995), foram coletadas amostras em cinco profundidades: $0,0-0,025 ; 0,025-$ 0,050; 0,050-0,10; 0,10-0,20; 0,0-0,20 m. A infiltração de água no solo foi realizada em outubro de 1999 pelo método dos cilindros concêntricos, segundo Cauduro \& Dorfman (1988). O ajustamento gráfico foi realizado pela equação de Kostiakov, segundo método recomendado por Cauduro \& Dorfman (1988). Foram escolhidos, al eatoriamente cinco pontos em três dos sistemas de manejo estudados para a instalação dos aparel hos. As leituras de lâmina infiltrada foram realizadas nos tempos 1, 2, $3,4,5,10,20,30,45,60,90$ e 120 min após o início do processo. Estas leituras foram interrompidas quando ocorreram três leituras constantes.

Para o ajustamento gráfico, a equação que mais se adapta a dados experimentais da mai oria dos solos e, por isso, a maisutilizadaé: $I=a^{n}{ }^{n}$ (EquaçãodeKostiakov), sendo I a infiltração acumulada (mm), t o tempo acumulado e a e $\mathbf{n}$ duas constantes dependentes do tipo de solo. Aplicando logaritmo a ambos os termos da equação, obteve-se uma equação de reta: log $\mathrm{I}=\log \mathrm{a}+\mathrm{n} \log \mathrm{t}$, ou seja, o gráfico de log I em função do log t representa uma reta sendo $n$ o coeficiente angular elog a o coeficientelinear. Com esteartifício gráfico, obtém-se I = f(t), equação muito útil, pois com ela pode-se calcular I para qualquer tempot.

Quadro 1. Resultados das análises químicas realizadas em amostra composta coletada na área em estudo

\begin{tabular}{|c|c|c|c|c|c|c|c|c|}
\hline Profundidade & pH & Ind SMP & $\mathbf{P}$ & $\mathbf{K}$ & $\mathrm{Na}$ & Al & $\mathrm{Ca}$ & Mg \\
\hline $\mathrm{cm}$ & & & \multicolumn{3}{|c|}{$\mathrm{mg} \mathrm{dm}^{-3}$} & \multicolumn{3}{|c|}{$\mathrm{mmol}_{\mathrm{c}} \mathrm{dm}^{-3}$} \\
\hline $0-10$ & 5,2 & 5,7 & 11,7 & 180 & 6,8 & 0 & 37 & 22 \\
\hline $10-20$ & 5,0 & 5,5 & 19,7 & 107 & 8,0 & 0 & 37 & 21 \\
\hline
\end{tabular}


A análise estatística constou de testes de comparação demédias (Duncan a 5\% designificância). Foi utilizado o programa estatístico SANEST (Zonta et al., 1984) para a realização da análise. Os resultados foram analisados comparando-se as variáveis entre sistemas de manejos para cada profundidade separadamente, comparações entre profundidades foram evitadas por não serem essas variáveis independentes.

\section{RESULTADOS E DISCUSSÃO}

Os valores médios percentuais de argila, silte e areia permitiram classificar o horizonte superficial do solo como franco-arenoso (Quadro 2).
A densidade do solo, na profundidade de 0,0$0,10 \mathrm{~m}$, foi significativamente maior no sistema plantio direto (Quadro 3). Entretanto não houve diferença significativa entre o campo nativo e o sistema convencional 1 , havendo desse em relação ao sistema convencional 2 . Os dois tratamentos conduzidos sob sistemas convencionais ( 1 e 2) não diferiram significativamente entre si.

A maior densidade do solo nas camadas superficiais do plantio direto com relação ao sistema convencional também foi encontrada por Secco et al . (1997), trabal hando em um Latossolo Vermel hoEscuro, bem como por Tormena et al. (1998), estudando o mesmo tipo de solo, em Ponta Grossa $(P R)$. Estes autores atribuíram este fato ao nãorevol vimento do sol o e ao tráfego de máquinas sobre

Quadro 2. Distribuição das partículas por tamanho e classificação textural de um Argissolo Vermelho submetido a diferentes sistemas de manejo, em duas profundidades

\begin{tabular}{|c|c|c|c|c|}
\hline \multirow{2}{*}{ Sistema de manejo } & \multicolumn{3}{|c|}{ Granulometria } & \multirow{2}{*}{ Classificação textural } \\
\hline & Areia & Silte & Argila & \\
\hline \multicolumn{5}{|c|}{$-\mathrm{g} \mathrm{kg}^{-1}$} \\
\hline \multicolumn{5}{|c|}{ Profundidade de $0,0-0,10 \mathrm{~m}$} \\
\hline $\begin{array}{l}\text { Convencional } 1 \\
\text { Convencional } 2 \\
\text { Plantio direto } \\
\text { Campo nativo }\end{array}$ & $\begin{array}{l}646 \\
637 \\
664 \\
670\end{array}$ & $\begin{array}{l}230 \\
242 \\
218 \\
216\end{array}$ & $\begin{array}{l}124 \\
121 \\
119 \\
114\end{array}$ & $\begin{array}{l}\text { Franco-arenosa } \\
\text { Franco-arenosa } \\
\text { Franco-arenosa } \\
\text { Franco-arenosa }\end{array}$ \\
\hline \multicolumn{5}{|c|}{ Profundidade de $0,10-0,20 \mathrm{~m}$} \\
\hline $\begin{array}{l}\text { Convencional } 1 \\
\text { Convencional } 2 \\
\text { Plantio direto } \\
\text { Campo nativo }\end{array}$ & $\begin{array}{l}584 \\
595 \\
651 \\
673\end{array}$ & $\begin{array}{l}295,0 \\
289 \\
226 \\
207\end{array}$ & $\begin{array}{l}121 \\
121 \\
123 \\
120\end{array}$ & $\begin{array}{l}\text { Franco-arenosa } \\
\text { Franco-arenosa } \\
\text { Franco-arenosa } \\
\text { Franco-arenosa }\end{array}$ \\
\hline
\end{tabular}

Quadro 3. Densidade do solo, porosidade total, macro e microporosidade de um Argissolo Vermelho submetido a diferentes sistemas de manejo

\begin{tabular}{|c|c|c|c|c|}
\hline Sistema de manejo & Densidade do solo(1) & Porosidade total(1) & Microporosidade ${ }^{(1)}$ & Macroporosidade $\mathrm{e}^{(1)}$ \\
\hline & $\mathrm{Mg} \mathrm{m}^{-3}$ & 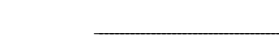 & $\%$ & 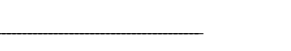 \\
\hline \multicolumn{5}{|c|}{ Profundidade de $0,0-0,10 \mathrm{~m}$} \\
\hline $\begin{array}{l}\text { Convencional } 1 \\
\text { Convencional } 2 \\
\text { Plantio direto } \\
\text { Campo nativo }\end{array}$ & $\begin{array}{l}1,55 \mathrm{bc} \\
1,52 \mathrm{c} \\
1,67 \mathrm{a} \\
1,60 \mathrm{~b}\end{array}$ & $\begin{array}{l}37,77 \mathrm{a} \\
39,08 \mathrm{a} \\
32,64 \mathrm{~b} \\
34,32 \mathrm{~b}\end{array}$ & $\begin{array}{l}24,70 a \\
24,98 a \\
24,20 a \\
25,27 a\end{array}$ & $\begin{array}{r}13,08 \mathrm{a} \\
14,10 \mathrm{a} \\
8,44 \mathrm{~b} \\
9,05 \mathrm{~b}\end{array}$ \\
\hline \multicolumn{5}{|c|}{ Profundidade de $0,10-0,20 \mathrm{~m}$} \\
\hline $\begin{array}{l}\text { Convencional } 1 \\
\text { Convencional } 2 \\
\text { Plantio direto } \\
\text { Campo nativo }\end{array}$ & $\begin{array}{l}1,61 \mathrm{a} \\
1,64 \mathrm{a} \\
1,63 \mathrm{a} \\
1,62 \mathrm{a}\end{array}$ & $\begin{array}{l}36,07 \mathrm{a} \\
35,31 \mathrm{a} \\
34,20 \mathrm{a} \\
33,98 \mathrm{a}\end{array}$ & $\begin{array}{l}26,94 \mathrm{a} \\
27,44 \mathrm{a} \\
23,90 \mathrm{~b} \\
22,92 \mathrm{~b}\end{array}$ & $\begin{array}{c}9,13 a b \\
7,87 b \\
10,30 a b \\
11,06 a\end{array}$ \\
\hline C.V. (\%) & 3,2 & 5,2 & 4,9 & 23,7 \\
\hline
\end{tabular}

(1) Médias seguidas por letras distintas, na mesma coluna, diferem entre si pelo teste de Duncan a $5 \%$. 
a superfície do solo. Os val ores relativamente altos de densidade do solo, encontrados em todos os sistemas avaliados, mais significativamente no sistema plantio direto com 1,67 $\mathrm{Mg} \mathrm{m}^{-3}$, estão dentro da faixa classificada por Reichardt (1985), para sol os arenosos. Valores altos de densidade do solo, da ordem de 1,7-1,8 $\mathrm{Mg} \mathrm{m}^{-3}$ em solo Podzólico Vermelho-Amarelo também são mencionados por Zanette et al. (1999), em trabal ho desenvolvido na Universidade Federal de Santa Maria (UFSM), em parcel as sob diversos tipos de manejo, bem como por Teixeira (1998), estudando o mesmo tipo de sol o em Pelotas (RS). Segundo Arshad et al. (1996), o valor mínimo de densidade para sol os arenosos acima da qual haveria restrição ao desenvol vimento de raízes é de 1,70-1,75 $\mathrm{Mg} \mathrm{m}^{-3}$. Tais trabalhos corroboram os val ores encontrados nestas avaliações, sendo tais valores considerados por estes autores nãoprejudiciais ao desenvolvimento de plantas nestes solos de textura franco-arenosa.

A densidade dosol onos quatrosistemas avaliados não diferiu entre si na camada de 0,10-0,20 m (Quadro 3), demonstrando que tanto os sistemas convencionais de manejo como o plantio direto não alteraram este parâmetro nesta profundidade em comparação com o campo nativo.

No que diz respeito à porosidade total, observase que, na camada de 0,0-0,10 m, os dois sistemas convencionais apresentaram maiores val ores deste parâmetro em relação aos sistemas plantio direto e campo nativo. Este fato deve-se ao resultado imediato dos trabalhos de preparo do solo nesta camada, "afrouxando" o sol o e possibilitando, assim, maior quantidade de poros. Do mesmo modo, nos dois sistemas sem preparo, o tráfego de máquinas no sistema plantio direto (plantio, tratos culturais e col heita) e o tráfego de animais no sistema campo nativo (pisoteio animal), a camada mais superficial tende a apresentar redução na porosidade.

Quantoaos resultados demacroemicroporosidade, verifica-se que os sistemas convencionais apresentaram mai or macroporosi dade na camada de 0,0-0,10 m (pelos mesmo motivos supracitados) e maior microporosidade na camada de 0,10-0,20 m, provavel mente como resultado das operações de preparo do solo ("pé-de-grade").

Os resultados obtidos de diâmetro médio ponderado, carbono orgânico são apresentados no quadro 4. Na camada de 0,0-0,10 m, o sistema plantio direto foi aquele que apresentou maior quantidade de carbono orgânico, seguido do campo nativo que não diferiu do sistema convencional 1 e foram superiores ao sistema convencional 2. O não revolvimento do sol o permitiu um aporte de carbono maior em relação aos sistemas convencionais de manejo. Na profundidade de 0,10-0,20 m, o campo nativo foi o sistema queapresentou o mai or diâmetro médio ponderado de agregados, diferindo estatisticamente dos demais sistemas. Observa-se
Quadro 4. Diâmetro médio ponderado (DMP) e carbono orgânico de um Argissolo Vermelho submetido a diferentes sistemas de manejo

\begin{tabular}{lcc}
\hline Sistema de manejo & DMP(1) & Carbono orgânico(1) \\
\hline \multicolumn{3}{c}{ Profundidade de $0,0-0,10 \mathrm{~m}$} \\
\multicolumn{4}{c}{ Mg ha-1 $^{-1}$} \\
Convencional 1 & $2,96 \mathrm{a}$ & $27,4 \mathrm{bc}$ \\
Convencional 2 & $2,93 \mathrm{a}$ & $25,7 \mathrm{c}$ \\
Plantio direto & $3,05 \mathrm{a}$ & $37,7 \mathrm{a}$ \\
Campo nativo & $3,52 \mathrm{a}$ & $30,9 \mathrm{~b}$ \\
\multicolumn{5}{c}{ Profundidade de 0,10-0,20 m } \\
Convencional 1 & $2,16 \mathrm{~b}$ & $24,8 \mathrm{~b}$ \\
Convencional 2 & $2,61 \mathrm{~b}$ & $28,4 \mathrm{ab}$ \\
Plantio direto & $2,61 \mathrm{~b}$ & $29,2 \mathrm{a}$ \\
Campo nativo & $3,04 \mathrm{a}$ & $28,2 \mathrm{ab}$ \\
C.V. (\%) & 21,3 & 8,9 \\
\end{tabular}

$\overline{(1)}$ Médias seguidas por letras distintas diferem entre si pelo teste de Duncan a $5 \%$.

ainda que o plantio direto não diferiu dos sistemas convencionais nesta profundidade.

A maior eficiência na agregação do solo do campo nativo $(0,10-0,20 \mathrm{~m})$ pode estar relacionada com a maior densidade de raízes apresentada pelas gramíneas perenes neste sistema, abrangendo um vol ume maior de solo, não somente a sua superfície. Os valores de carbono orgânico do solo sob campo nativo, entretanto, não foram significativamente superiores aos dos outros sistemas estudados. Pelo contrário, foram inferiores aos do plantio direto e superiores apenas aos do sistema convencional 2 na camada de 0,0-0,10 m. Na camada de 0,10-0,20 m, entretanto, as diferenças não foram significativas.

A matéria orgânica é considerada por muitos pesquisadores como o principal agente de estabilização dos agregados do solo (Tisdall \& Oades, 1982; Castro Filho et al ., 1998; Gang Lu et al .,1998), sendo uma al ta correl ação entre essa e a agregação do sol o um resultado esperado em tratamentos que apresentem diferenças no teor de carbono orgânico. Os resultados encontrados neste estudo, no entanto, não confirmaram as afirmativas destes autores, pois o maior conteúdo de carbono orgânico no plantio direto não se refletiu em diferenças significativas no diâmetro médio de agregados. O fato de ter $\mathrm{O}$ sistema plantio direto sido estabelecido há apenas 3 anos pode ter acarretado reflexos positivos na estabilidade estrutural deste sol ocom características arenosas.

A pequena variação encontrada entre os valores de DMP, entre os sistemas de manejo e profundidades avaliadas, pode ser motivada pelo método utilizado que, segundo Silva \& Mielniczuk (1998), não distingue os agregados recém-formados 
daqueles que, além de formados, já sofreram um processo de estabilização. Por esse motivo, nos sistemas convencionais, a agregação pode ter sido provocada por ação de compressão das partículas do solo, sem, entretanto, ocorrerem os mecanismos que contribuem para sua estabilização. Castro Filho et al (1998) apresentaram uma boa avaliação sobre os métodos utilizados, comparando os resultados em relação à peneira utilizada após a col eta no campo.

Os resultados da taxa de infiltração da água no solosão mostrados no quadro 5 efigura la. Observase que os val ores da taxa de infiltração nos diferentes sistemas não apresentaram diferenças significativas entre si. A análise dos dados mostrou valores nãosignificativos pelo teste $\mathrm{F}$, a $5 \%$, tendo a infiltração um valor médio de $15 \mathrm{~mm} \mathrm{~h}^{-1}$ e um coeficiente de variação de $26,4 \%$.

Os val ores de umidade determinados anteriormente à determinação da taxa de infiltração evidenciaram que não houve efeito da umidade inicial do sol o nesta determinação. Estes valores de umidade foram baixos e explicam a alta taxa de infiltração inicial encontrada em todos os sistemas estudados.

Os val ores da taxa de infiltração são considerados altos (15-30 $\mathrm{mm} \mathrm{h}^{-1}$ ), segundo classificação sugerida por Reichardt (1990), em razão da textura francoarenosa deste solo, embora os val ores de densidade e porosidade sejam, respectivamente, altos e baixos (Quadro 2).
Quadro 5. Taxa de infiltração determinada pelo método dos cilindros concêntricos em cinco repetições (R) de um Argissolo Vermelho submetido a diferentes sistemas de manejo

\begin{tabular}{|c|c|c|c|c|c|c|}
\hline Sistema de manejo(1) & $\mathbf{R} 1$ & $\mathbf{R 2}$ & $\mathbf{R 3}$ & R4 & $\mathbf{R 5}$ & Média(2) \\
\hline & & -1 & гाт & 1 & - & \\
\hline $\begin{array}{l}\text { Convencional } 1 \\
\text { Plantio direto } \\
\text { Campo nativo }\end{array}$ & $\begin{array}{l}12 \\
14 \\
20\end{array}$ & $\begin{array}{l}10 \\
12 \\
12\end{array}$ & $\begin{array}{l}14 \\
14 \\
28\end{array}$ & $\begin{array}{l}16 \\
16 \\
16\end{array}$ & $\begin{array}{l}13 \\
14 \\
14\end{array}$ & $\begin{array}{l}13 a \\
14 a \\
18 a\end{array}$ \\
\hline C.V. (\%) & & & & & & 26,4 \\
\hline
\end{tabular}

(1) Para o sistema convencional 2, esta determinação não foi re alizada. ${ }^{(2)}$ Médias seguidas por letras distintas diferem entre si pelo teste de Duncan a $5 \%{ }^{(2)}$ Determinação não realizada.

ConformeBrito et al. (1996) e Pruski et al . (1997), os val ores de infiltração básica devem ser analisados com cuidado, quando se avalia a maior, ou menor, taxa de infiltração, pois o infiltrômetro de cilindros concêntricos, utilizado neste estudo, apresenta, geral mente, resultados superiores aos do infiltrômetro de aspersão, que utiliza chuva artificial (Levien et al., 2000). Os resultados obtidos por Brito et al. (1996), comparando a velocidade de infiltração entre os dois métodos citados para as condições de solo com cobertura morta mostram que o infiltrômetro de cilindros concêntricos superestima em 2,5 vezes os val ores obtidos com infiltrômetro de aspersão.
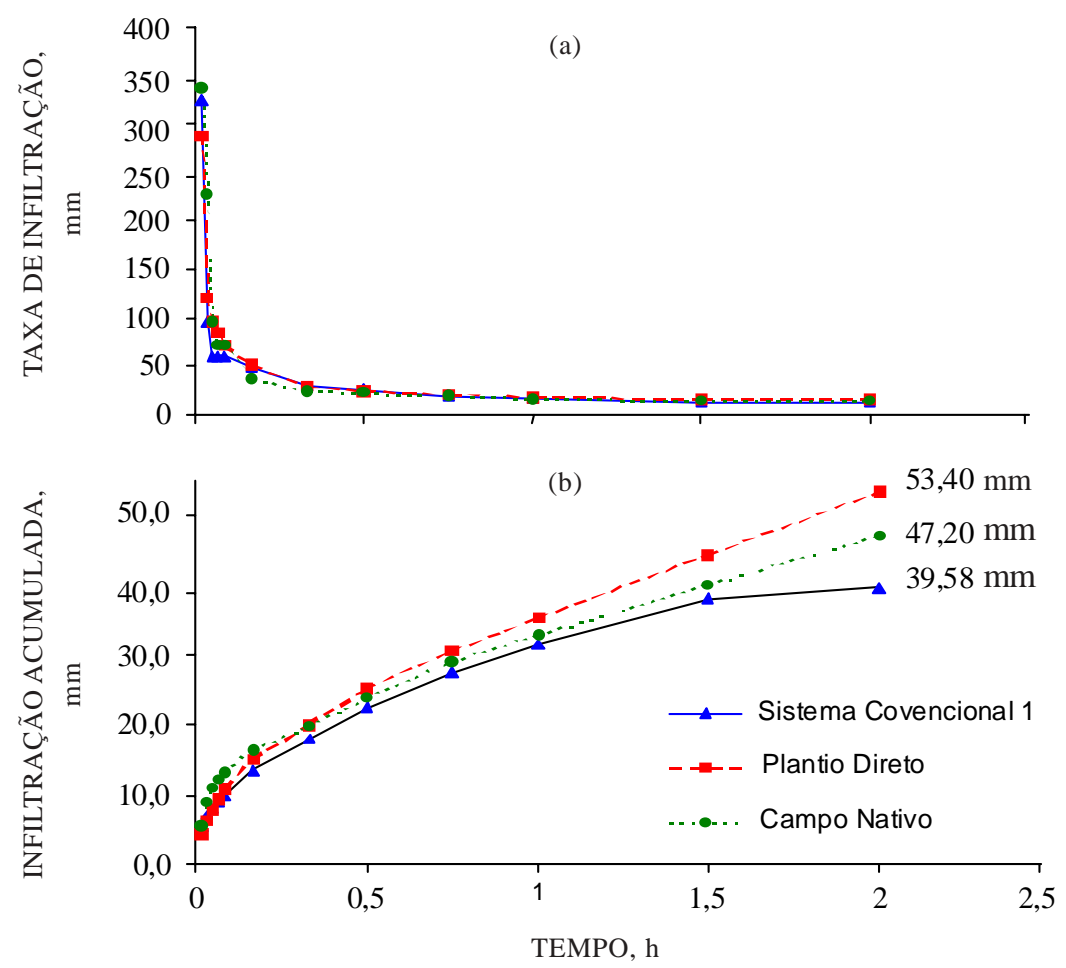

Figura 1. Taxa de infiltração $\left(\mathrm{mm} \mathrm{h}^{-1}\right)$ - (a) e infiltração acumulada $(\mathrm{mm})$ - (b), de um Argissolo Vermelho submetido a diferentes sistemas de manejo de acordo com o tempo (h). 
Deacordo com Eltz et al . (1989), o método utilizado (inundação com cilindros concêntricos) não provoca selamento superficial dos poros por impacto de gotas, o que revela forte influência sobre a velocidade de infiltração da água no solo. A utilização do método que utiliza chuva artificial poderia acarretar resultados diferentes, permitindo que os tratamentos com manutenção de cobertura do solo apresentassem valores ainda maiores. Os efeitos de selamento superficial verificados por Eltz et al. (1989) nos sistemas convencionais de manejo, bem como os efeitos do aumento da tortuosidade do fluxo superficial (menor escorrimento superficial), não foram constatados pelo método utilizado.

A figura la mostra os gráficos da taxa de infiltração básica obtidos nos três sistemas estudados. A pequena diferença entreos tratamentos também se verificou na taxa inicial de infiltração. Observa-se que a menor taxa de infiltração inicial ocorreu no sistema plantio direto $\left(288 \mathrm{~mm} \mathrm{~h}^{-1}\right)$ seguida do sistema convencional $1\left(324 \mathrm{~mm} \mathrm{~h}^{-1}\right)$ e do campo nativo (336 $\left.\mathrm{mm} \mathrm{h}^{-1}\right)$. Abrão et al. (1979) encontraram velocidade de infiltração inicial mais el evada nos tratamentos que sofreram maior mobilização, provavelmente, segundo os mesmos autores, em decorrência da destruição da estrutura nos primeiros $0,05 \mathrm{~cm}$.

A figura 1b mostra os resultados de infiltração acumulada dos três sistemas de manejo estudados. A infiltração acumulada foi maior no plantio direto $(53,4 \mathrm{~mm})$, seguido do campo nativo $(47,2 \mathrm{~mm})$ e sistema convencional 1 (39,6 mm).

Estes valores indicam que, no sistema plantio direto, é maior a quantidade de água infiltrada no mesmo intervalo de tempo, em relação aos outros dois sistemas estudados. Este fato pode significar menor escorrimento superficial e menor erosão, conforme também constataram Eltz et al. (1989).

A fim estimar a infiltração acumulada em determinado período de tempo, os dados, para cada sistema de manejo, foram ajustados à equação de Kostiakov (Libardi, 2001).

O quadro 6 mostra as equações ajustadas para cada sistema de manejo, bem como o coeficiente de determinação $\left(R^{2}\right)$ do ajuste. Estes coeficientes foram el evados, mostrando que houve um bom ajuste entre os dados observados e estimados. A curva de infiltração representada pelas figura 1 e, ou, as equações do quadro 5 são de grande valor prático. Elas nos fornecem informações sobre a capacidade do solo de absorver água.

A equação de Kostiakov, embora empírica, é bastante útil em aplicações de irrigação, pela sua simplicidade e pelo fato de, para curtos intervalos de tempo (até $10^{5} \mathrm{~s}$ ), ajustar-se razoavel mente bem para uma grande quantidade de solos (Libardi, 2001).
Quadro 6. Equação de Kostiakov ajustada à infiltração instantânea - i (cm) - de acordo com o tempo - $t\left(\mathrm{~min}^{-1}\right)$ - de um Argissolo Vermelho submetido a diferentes sistemas de manejo

\begin{tabular}{lll}
\hline Sistema de manejo & Kostiakov & $\mathbf{R}^{\mathbf{2}}$ \\
\hline Convencional 1 & $\mathrm{i}=0,5098 \mathrm{t}^{0,4361}$ & 0,9971 \\
Plantio direto & $\mathrm{i}=0,4645 \mathrm{t}^{0,4984}$ & 0,9992 \\
Campo nativo & $\mathrm{i}=0,6498 \mathrm{t}^{0,4017}$ & 0,9869 \\
\hline
\end{tabular}

As determinações realizadas permitiram identificar mudanças nas propriedades físicas deste ArgissoloVermel ho, quando submetido a diferentes sistemas de manejo. Estas alterações foram verificadas principalmente nos parâmetros relacionados com a porosidade do solo. Dado o pequeno tempo de uso (três anos) do sistema plantio direto, não foi possível verificar grandes ganhos estruturais no solo e, conseqüentemente, na recuperação de possíveis danos provocados por muitos anos de condução pelo sistema convencional . Do mesmo modo que para atributos quími cos do solo, adotam-se cinco anos como tempo para estabilização das al terações provocadas pel o não-revol vimento do solo, para os atributos físicos, deve ser necessário um tempo semelhante ou até maior para que se possam verificar mel horias estruturais do solo.

\section{CONCLUSÕES}

1. O sistema plantio direto não apresentou melhorias na agregação do solo significativas em relação aos dois sistemas convencionais estudados, após três anos de condução.

2. Os sistemas convencionais de preparo do solo apresentaram porosidade total e macroporosidade maiores que os dos sistemas plantio direto e campo nativo até $0,10 \mathrm{~m}$ de profundidade.

3. O sistema plantio direto apresentou maior índice de carbono orgânico na camada de 0,10 m, não se refletindo em aumento no DMP.

\section{AGRADECIMENTOS}

À Embrapa/CPACT, pelo apoio e oportunidade do desenvol vimento destetrabal ho, eà CAPES, pela bolsa ao primeiro autor.

\section{LITERATURA CITADA}

ABRÃO, P.U.R.; GOEPFERT, C.F.; GUERRA, M.; ELTZ, F.L.F. \& CASSOL, E.A. Efeitos de sistemas de preparo do solo sobre características de um Latossolo Roxo distrófico. R. Bras. Ci. Solo, 3:169-172, 1979. 
ALBUQUERQUE, J.A.; REINERT, D.J .; FIORIN, J.E.; RUEDELL, J .; PETRERE, C. \& FONTIMELLI, F. Rotação de culturas e sistemas de manejo do solo: efeito sobre a forma da estrutura do solo ao final de sete anos. R. Bras. Ci. Solo, 19:115-119, 1995.

ARSHAD, M.A.; LOWERY, B. \& GROSSMAN, B. Physical tests for monitoring soil quality. In: DORAN, J.W. \& J ONES, A.J ., eds. Methods for assessing soil quality. Madison, 1996. p.123-141.

BARCELOS, A.A.; CASSOL, E.A. \& DENARDIN ,J .E. I nfiltração de água em um Latossolo Vermel ho-E scuro sob condições dechuva intensa em diferentes sistemas demanejo. R. Bras. Ci. Solo, 23:35-43, 1999.

BLAKE, G.R. \& HARTGE, R.H. Bulk density. In: KLUTE, A., ed. Methods of soil analysis. 2.ed. Madison, 1986. p.363381.

BRITO, L.T.L.; LOUREIRO, B.T.; DENICULI, W.; RAMOS, M.M. \& SOARES, J.M. Influência do método na determinação da vel ocidade de infiltração. R. Bras. Ci. Solo, 20: 503-507, 1996.

CASTRO FILHO, C.; MUZILLI, O. \& PODANOSCHI, A.L. Estabilidade dos agregados e sua relação com o teor de carbono orgânico num Latossolo Roxo distrófico, em função de sistemas de plantio, rotações de culturas e métodos de preparo das amostras. R. Bras. Ci. Solo, 22:527-538, 1998.

CAUDURO, F.A. \& DORFMAN, R. Manual de ensaios de laboratório e de campo para irrigação e drenagem. Porto Alegre, Pallotti, 1988. 216p.

DENARDIN, J.E. \& KOCHHANN, R.A. Pesquisa de desenvol vimento em sistema plantio direto no Rio Grande do Sul. In: CONGRESSO BRASILEIRO DE CIÊNCIA DO SOLO, 26., Rio de J aneiro, 1997. Palestra. Rio de J aneiro, 1997. CD ROOM

ELTZ, F.L.F.; PEIXOTO, R.T.G. \& JASTER, F. Efeitos de sistemas de preparo do solo nas propriedades físicas e químicas de um Latossolo Bruno álico. R. Bras. Ci. Solo, 13: 259-267, 1989.

EMPRESA BRASILEIRA DE PESQUISA AGROPECUÁRIA EMBRAPA. Centro Nacional de Pesquisa de Solos. Manual de métodos de análise de solo. Rio de J aneiro, 1997. 212p.

EMPRESA BRASILEIRA DE PESQUISA AGROPECUÁRIA EMBRAPA. Centro Nacional de Pesquisa de Solos. Sistema brasileiro de classificação de solos. Produção de informação. Brasília, 1999. 422p.

GANG, L.U.; SAKAGAMI, K.; TANAKA, H. \& HAMADA, R. Role of soil organic matter in stabilization of water-stable aggregates in soils under different types of land use. Soil Sci. Plant Nutr., 44:147-155, 1998.

GEE, G.W. \& BAUDER, J .W. Particle-sizeAnalysis. In: KLUTE, A., ed. Methods of soil analysis. 2.ed., Madison, 1986. p.383411.

LEVIEN, R.; LIER, Q.J .V. \& ALVES, A.G.C. I nfluence of surface crust on water infiltration rates measured by a rotatingboom rainfall simulator and a double-cylinder device. $\mathrm{R}$. Bras. Ci. Solo, 24:479-486, 2000.
LIBARDI, P.L. Dinâmica da água no solo. Piracicaba, Libardi, 2001. 497p.

MOTA, F.S. \& GOEDERT, C.O. Evapotranspiração no Rio Grande do Sul. Pesq. Agropec. Bras., 1:155-163, 1966.

PALMEIRA, P.R.T.; PAULETTO, E.A.; TEIXEIRA, C.F.A.; GOMES, A.S. \& SILVA, J .B. Agregação de um Planossolo submetido a diferentes sistemas de manejo. R. Bras. Ci. Solo, 23:189-195, 1999.

PRUSKI, F.F.; VENDRAME, V.; OLIVEIRA, E.F.; BALBINO, L.C.; FERREIRA, P.A.; WERLANG, L. \& CARVALHO, L.T. Infiltração da água num Latossolo Roxo. Pesq. Agropec. Bras., 32:77-84, 1997

REICHARDT, K. Processos de transferência no sistema soloplanta-atmosfera. Campinas, Fundação Cargill, 1985. 445p.

REINERT, D.J. Soil structural form and stability induced by tillage in a typic Hapludalf. Michigan, Michigan State University, 1990. 128p. (Tese de Doutorado)

REINERT, D.J . Recuperação de sol os em sistemas agropastoris; Curso sobre aspectos básicos de fertilidade e mi crobiologia do solo no sistema plantio direto. Plantio Direto, 4:25-44, 1997.

SECCO, D.; DA ROS, C.O.; FIORIN, J .E.; PAUTZ, C.V. \& PASA, L. Efeito de sistemas de manejo nas propriedades físicas de um Latossolo Vermel ho-Escuro. R. Ci. Rural, 27:35-48, 1997.

SILVA, I.F . \& MIELNICZUK, J. Ação do sistema radicular de plantas na formação e estabilização de agregados do solo. R. Bras. Ci. Solo, 21: 113-117, 1997.

SILVA, I.F. \& MIELNICZUK, J. Sistemas de cultivo e características do sol o afetando a estabilidade de agregados. R. Bras. Ci. Solo, 22:311-317, 1998.

TEDESCO, M.J .; GIANELLO, C.; BISSANI, C.A.; BOHNEN, H. \& VOLKWEISS, S.J . Análise de solo, plantas e outros materiais. Porto Alegre, Universidade Federal do Rio Grande do Sul, 1995. 174 p. (Boletim Técnico, 5)

TEIXEIRA, C.F.A. I nfluência de sistemas de cultivo em plantio direto em alguns atributos físicos de um Podzólico Vermelho-Amarelo. Pelotas: Universidade Federal de Pelotas, Universidade Federal de Pelotas, 1998. 59p. (Tese de Mestrado)

TISDALL, J .M. \& OADES, L.M. Organic matter and water stable aggregates in soils. J. Soil Sci., 33:141-163, 1982.

TORMENA, C.A.; ROLOFF, G. \& SÁ, J.C.M. Propriedades físicas do solo sob plantio direto influenciadas por calagem, preparo inicial etráfego. R. Bras. Ci. Solo, 22:301-309, 1998.

ZANETTE, A.; REINERT, D.J .; REICHERT, J .M.; SILVA, V.R.; BACH, A.V.; RUBIN, R.B. \& GENRO J R., S.A. Relações entre poros biológicos e atributos físicos no sistema plantio direto. In: CONGRESSO BRASILEIRO DE CIÊNCIA DO SOLO, 28., Brasília, 1999. Anais. Brasília, 1999. CD ROOM

ZONTA, E.P.; MACHADO, A.D. \& SILVEIRA J ÚNIOR, P. SANEST: Sistema de análise para microcomputadores. Registrado na Secretaria especial de Informática sob no 066060-categoria A. Pelotas, Universidade Federal de Pelotas, 1984. 